\title{
Chapter 21 \\ Development of Powder Jet Deposition Technique and New Treatment for Discolored Teeth
}

\author{
Kuniyuki Izumita, Ryo Akatsuka, Akihiko Tomie, Chieko Kuji, \\ Tsunemoto Kuriyagawa, and Keiichi Sasaki
}

\begin{abstract}
The powder jet deposition (PJD) process is for creation of a hydroxyapatite (HA) layer on human teeth. To develop the PJD device, the layer-forming properties have improved. Created HA layers with a new handpiece-type PJD device demonstrate excellent material properties in vitro. Titanium dioxide $\left(\mathrm{TiO}_{2}\right)$ is known to cause whitening because of the selective reflection of the light. Therefore, we assessed the possibility of using the creation of $\mathrm{TiO}_{2}-\mathrm{HA}$ layers with the new PJD device as a new treatment for discolored teeth. In this study, the microstructural and mechanical properties of $\mathrm{TiO}_{2}$-HA layers were evaluated under the same conditions of the previous study. These properties were evaluated before and after 500 cycles of thermal cycling $\left(5-55^{\circ} \mathrm{C}\right)$. Furthermore, the CIE L*a* $b^{*}$ color system was used for color measurement and $\Delta \mathrm{E}^{*}$ values for color differences were calculated. The maximum thickness of the $\mathrm{TiO}_{2}$-HA layers was about $60 \mu \mathrm{m}$. There were no significant differences in thickness, hardness, or bonding strength before and after thermal cycling. The layers showed an increased $\mathrm{L}^{*}$ parameter and a decreased $\mathrm{b}^{*}$ parameter, and the color difference $\Delta \mathrm{E}^{*}$ was approximately 6.7 units. Creation of $\mathrm{TiO}_{2}-\mathrm{HA}$ layers by PJD might be a valuable new treatment for discolored teeth.
\end{abstract}

Keywords Powder jet deposition $\bullet$ Hydroxyapatite $\bullet$ Titanium dioxide $\bullet$ Discolored teeth $\bullet$ Thermal cycle

\footnotetext{
K. Izumita $(\bowtie) \bullet R$. Akatsuka

Division of Advanced Prosthetic Dentistry, Graduate School of Dentistry, Tohoku University,

4-1 Seiryo-machi, Aoba-ku, Sendai, Miyagi 980-8575, Japan

e-mail: k-izumita@dent.tohoku.ac.jp
}

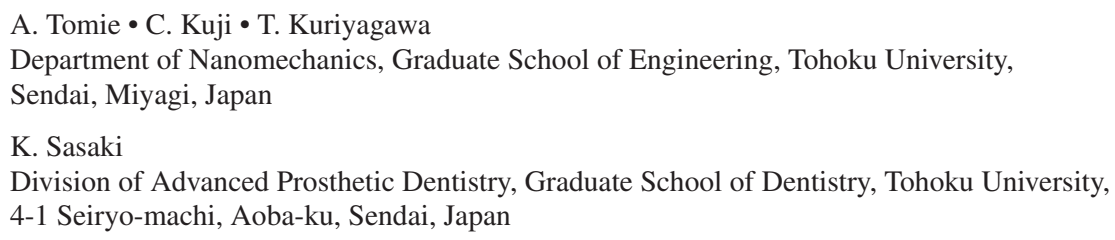




\subsection{Introduction}

The biomaterials used for dental restorative treatments have quite different chemical compositions and mechanical properties from tooth substances which are enamel and dentin. Even if the adhesion technique is properly applied, these differences in properties between restorative materials and tooth substance can give rise to different mechanical, thermal, or chemical stresses in the oral cavity and can lead to clinical problems such as drop-off of the restorative material from the tooth or secondary caries [1]. In our previous studies, we presented the possibility of applying a layer of HA as a new restorative material with chemical, compositional, and mechanical properties corresponding to the tooth substance [2,3]. A newly developed advanced technology called powder jet deposition (PJD) was used to create the HA layers. The PJD technique was originated in abrasive jet machining (AJM), which is one of the precise processing methods for hard-brittle materials through an average particle size of approximately $10-20 \mu \mathrm{m}$, and it is also a well-established or developed noncontact mechanical removal process. When smaller particles of ceramic or metal, approximately $1-3 \mu \mathrm{m}$ in diameter, were blasted onto ceramic substrate by the AJM process, the particles were deposited on the substrate. This is called the PJD technique. The PJD technique is performed at room temperature and at atmospheric pressure, which enables it to be used with HA particles for the creation of HA layers on human teeth [1].

White and well-aligned teeth are the most important aspect of a smile; discolored teeth can influence self-esteem and professional relationships [4, 5]. Tooth discoloration is classified as an intrinsic or extrinsic depending on its cause [4-7]. Discoloration caused by extrinsic factors, including chromogens derived from coffee, cigarettes, or dental plaque, is generally removed by professional tooth polishing [4-8]. Treatment of teeth with intrinsic discoloration, which may be drug related (tetracycline) or caused by pulp tissue remnants after endodontic therapy [9], is done by bleaching with radical agents or tooth restoration with dental materials such as composite resin. Several studies $[10,11]$ have reported side effects of tooth bleaching agents, such as tooth hypersensitivity, irritation of dental pulp, and decreased hardness of enamel. These observations suggest the need for a new treatment for discolored teeth including the creation of an interface layer with material similar to the tooth and no adverse tooth substance and pulpal response.

In daily life, $\mathrm{TiO}_{2}$ is a common additive in many foods, pigments, and other consumer products used. $\mathrm{TiO}_{2}$-based ingredients are mostly used as a coloring agent [12]. According to a study carried out to determine the influence of $\mathrm{TiO}_{2}$ particles in a concentration of $0.10-0.25 \%$, the particles induced a whiter tooth color and simulated the opalescence of human enamel [13]. We therefore proposed the possibility of applying creation of $\mathrm{TiO}_{2}$-HA layers on the human tooth surface by noble PJD process as a new treatment for discolored teeth. 


\subsection{The Initial Development of PJD Process and Evaluation of HA Layers}

The first previous study aimed to create HA layers by PJD with manipulating the blasting nozzle above human enamel and to evaluate the microstructural properties of HA layers in vitro. The caries-free human molars extracted for orthodontic treatment with the informed consent of the patients were used. For each specimen, the crown of the molar was severed using a diamond blade cutter and fixed onto an aluminum scanning electron microscope (SEM) stage using an epoxy resin-based adhesive agent. A flat enamel surface perpendicular to the enamel rods was prepared by polishing each specimen with a silicon carbide grinding wheel, using diamond pastes, to obtain an identical surface. The specimens were treated by PJD, using HA particles synthesized by Sangi Co., Ltd. (Tokyo, Japan). A dental PJD device developed by Kuriyagawa and Sendai Nikon Co., Ltd. (Miyagi, Japan) was used to create the HA layers on the enamel substrate of specimens. The PJD device with a blasting nozzle was about $3 \mathrm{~cm}$ long, $4 \mathrm{~cm}$ wide, and $4 \mathrm{~cm}$ tall. In this system, when the high-speed solenoid value is opened, the difference in cross-sectional area across the particle feed tube generates negative pressure at the particle charging port located in the middle of the particle feed tube. The negative pressure causes particles to be taken up into the tube. The high-speed solenoid value is controlled by a personal computer and can be opened and closed at a frequency of approximately $100 \mathrm{~Hz}$. The particles are carried to the mixing chamber, where they are mixed with a continuous flow of accelerating gas and then blasted from the nozzle. The details of experimental conditions are shown in Table 21.1. The specimens were fixed on a stage, with their enamel surface perpendicular to the nozzle. The layers were polished using diamond polishing paste (Dia Polisher Paste; GC, Tokyo, Japan) and a felt wheel for $30 \mathrm{~s}$ with intermittent pressure of 5,000 $\mathrm{g}$ [2]. To evaluate the microstructure, the cross section of the HA layers was observed by SEM (JSM-6500F, JEOL, Tokyo, Japan). Three-dimensional profiles were obtained and surface thickness evaluated using a three-dimensional noncontact measurement system (NH-3;

Table 21.1 The experimental conditions

\begin{tabular}{l|l|l|l}
\hline The first, second, and present study shows captions "29.2," "29.3," and "29.4," respectively \\
\hline Parameters & $\begin{array}{l}\text { The first } \\
\text { study }\end{array}$ & $\begin{array}{l}\text { The second } \\
\text { study }\end{array}$ & The present study \\
\hline Substrate & Enamel & Enamel & Enamel \\
\hline Particles & HA & HA & $\mathrm{TiO}_{2}$-HA \\
\hline Size of particles $[\mu \mathrm{m}]$ & 4.7 & $3.0 \pm 1.0$ & $3.0 \pm 1.0$ \\
\hline Accelerating gas pressure $[\mathrm{MPa}]$ & 0.5 & 0.5 & 0.5 \\
\hline Feed gas pressure $[\mathrm{MPa}]$ & - & 0.5 & 0.5 \\
\hline Blasting angle $\left[{ }^{\circ}\right]$ & 90 & 90 & 90 \\
\hline Blasting time $[\mathrm{s}]$ & - & 30 & 30 \\
\hline Gap between nozzle and substrate $[\mathrm{mm}]$ & 1 & 1 & 1
\end{tabular}


Mitaka Kohki, Tokyo, Japan). The HA particles were densely packed, and there were no obvious gaps between the HA layers and the enamel substrate. The maximum and average thickness was approximately $40 \mu \mathrm{m}$ and $30 \mu \mathrm{m}$, respectively.

\subsection{New Handpiece-Type PJD Device and Evaluation of Thermal Stress in HA Layers}

The aims of the second previous study were to use the PJD device, newly developed for use with dental handpieces, to create the HA layer, and to evaluate the microstructural and mechanical properties of the HA layer, in particular the effects of thermal stress. To apply the HA layers, a newly developed PJD device, of similar size to normal dental handpieces, was used (Fig. 21.1). The HA particles were mixed in the camber of the PJD device with a continuous flow of accelerating gas (air), and then blasted form the nozzle onto the enamel substrate at room temperature $\left(25^{\circ} \mathrm{C}\right)$ and atmospheric pressure $(1 \mathrm{~atm})$. Detailed experimental conditions of this study are shown in Table 21.1. For thermal-cycling procedure, a computercontrolled two-temperature thermal-cycler (Thermal-cycling K-179; Tokyo-Giken, Tokyo, Japan) was used. Two water baths were maintained at $5{ }^{\circ} \mathrm{C}$ and $55^{\circ} \mathrm{C}$. Each cycle consisted of $20 \mathrm{~s}$ immersion in each water bath and a travel time of $10 \mathrm{~s}$. The water baths were constantly stirred with stirrers, and the variation in the temperature of each water bath was within $1{ }^{\circ} \mathrm{C}$ of the set temperature $[2,14]$. The specimens were first immersed in distilled water at $37{ }^{\circ} \mathrm{C}$ for 1 day. After the immersion, the specimens underwent 500 thermal cycles [2]. To evaluate their microstructure, the cross section of the HA layers was observed by SEM. The three-dimensional profiles, including surface thickness, of the layers were evaluated using a threedimensional noncontact measurement system. To evaluate the mechanical properties of the layers, micro-Vickers hardness was measured using a dynamic microhardness tester (FM-ARS 9000; Future-Tech, Kawasaki, Japan). A load of 100 gf was applied for $5 \mathrm{~s}$ using a pyramid-shaped die; the depth of the impression was used to
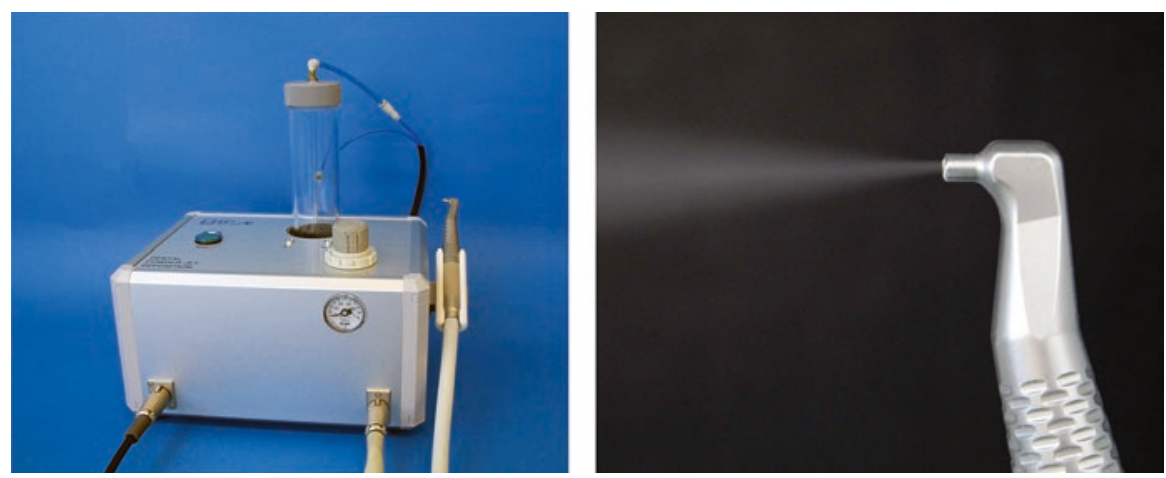

Fig. 21.1 New handpiece-type PJD device 
calculate the hardness of the specimens $[2,15]$. Furthermore, the bonding strength of the HA layers to the enamel substrates was evaluated using a micro-tensile test (Romulus; Quad Group, Spokane, WA, USA) [2, 16]. An epoxy pre-coated alumina stud was placed perpendicularly onto the surface of the specimen. The area of the surface coated with the epoxy glue was approximately $2.7 \mathrm{~mm}$ in diameter. After curing at $150{ }^{\circ} \mathrm{C}$ for $1 \mathrm{~h}$, the specimen was set into the testing machine and gripped. The study was pulled until destruction of the specimen, and the bonding strength was determined as the maximum load recorded [2]. The microstructural properties (SEM images, three-dimensional profiles, and surface thickness) and the mechanical properties (micro-Vickers hardness and bonding strength) were evaluated before and after the abovementioned thermal-cycling process. The HA particles in the deposited layer were densely packed, and the surface of the HA layer was unchanged after thermal cycling. The maximum and average thickness were approximately $60 \mu \mathrm{m}$ and $50 \mu \mathrm{m}$, respectively. There were also no significant differences in the hardness and the bonding strength of HA layer before and after thermal cycling.

\subsection{New Handpiece-Type PJD Device and Evaluation of Thermal Stress in $\mathrm{TiO}_{2}$-HA Layers}

These previous studies have led to an understanding of the excellent properties of HA layers created by PJD process. However, the microstructural and mechanical properties of $\mathrm{TiO}_{2}-\mathrm{HA}$ layers have not yet been clarified. The objectives of the present study are to evaluate the microstructural and mechanical properties of $\mathrm{TiO}_{2}-\mathrm{HA}$ layers before and after thermal-cycling tests under the same conditions of the second precious study. To apply the $\mathrm{TiO}_{2}$-HA layers, a newly developed PJD device was used. The specimens were treated by with $\mathrm{PJD}$, using $\mathrm{HA}^{-\mathrm{TiO}_{2}}$ particles synthesized by Sangi Co., Ltd. (Tokyo, Japan), in which $\mathrm{TiO}_{2}$ was added as a color regulator [17]. The microstructural properties of $\mathrm{TiO}_{2}-\mathrm{HA}$ layers were evaluated from SEM and the three-dimensional profiles: surface thickness. The mechanical properties were evaluated from micro-Vickers hardness and bonding strength. These properties were evaluated before and after the abovementioned 500 cycles of thermal cycling. $\mathrm{TiO}_{2}-\mathrm{HA}$ particles were also densely packed; the maximum and average thickness were approximately $60 \mu \mathrm{m}$ and $50 \mu \mathrm{m}$, respectively. There were no significant differences in thickness, hardness, or bonding strength before and after thermal cycling.

\subsection{Color Differences of $\mathrm{TiO}_{2}$-HA Layers}

In the previous study, the degree to which $\mathrm{TiO}_{2}$-HA layers influence tooth whitening has not been well documented. The objectives of the present study were also to evaluate the color differences of $\mathrm{TiO}_{2}-\mathrm{HA}$ layers. The color was measured using the 
CIE $L^{*} a^{*} b^{*}$ color measurement system on the spectrophotometer (CMS-35FS/C; Murakami Color Research Laboratory, Tokyo, Japan) [17]. The CIE $L^{*} a^{*} b^{*}$ system is composed of three coordinates: $L^{*}$ (lightness, from $0=$ black to $100=$ white), $a^{*}$ (from $-\mathrm{a}=$ green to $+\mathrm{a}=$ red), and $\mathrm{b}$ (from $-\mathrm{b}=$ blue to $+\mathrm{b}=$ yellow). The area of irradiation and color measurement were $\varphi 6 \mathrm{~mm}$ and $\varphi 3 \mathrm{~mm}$, respectively, and the illuminating and viewing configuration used was CIE diffuse $/ 8^{\circ}$ geometry $[16,18]$. Each specimen was chromatically measured three times under different conditions - (1) before and (2) after creation of the $\mathrm{TiO}_{2}-\mathrm{HA}$ layer - and the average values were calculated. The total color differences between the abovementioned three conditions were calculated according to the following equation:

$$
\Delta E^{*}=\sqrt{\left(\Delta L^{*}\right)^{2}+\left(\Delta a^{*}\right)^{2}+\left(\Delta b^{*}\right)^{2}}
$$

Color differences between conditions (1) and (2) were calculated as $\Delta E$ which evaluates the degree of whitening.

The $L^{*}, a^{*}$, and $b^{*}$ color parameters and color differences of the three measured conditions are listed in Table 21.3. The $L^{*}$ color parameter significantly increased between conditions (1) and (2). The $a^{*}$ color parameter did not significantly change between any of the conditions. In contrast, the $b^{*}$ color parameter significantly decreased between conditions (1) and (2) ( $p>0.05$, Steel-Dwass multiple comparison test). From these data, the calculated total color difference was $\Delta E$ (Table 21.4).

\subsection{Discussions}

In our previous and present study, SEM images clearly showed that the HA and $\mathrm{TiO}_{2}$-HA particles were densely packed in the layers and there were no visible pores or cracks between layer and enamel substrate. Cross-sectional SEMs reported in a previous study on the microstructure of a plasma-sprayed $50-\mu \mathrm{m}$-thick HA coating on titanium alloy revealed the presence of cracks in the titanium alloy and along the HA coating-substrate interface [19]. Such cracks may be directly related to the coating bonding strength [20] and may affect the long-term stability of HA coatings [21, 22]. Although the substrate was different, it could be considered that HA layers with good material properties are more effectively created using the PJD process than the abovementioned plasma spray-coating technique. From the three-dimensional viewing of $\mathrm{HA}$ and $\mathrm{TiO}_{2}-\mathrm{HA}$ layers created with new handpiece-type PJD device, the maximum and the average layer thickness were approximately $60 \mu \mathrm{m}$ and $50 \mu \mathrm{m}$, respectively. Using of a new developed PJD device enabled us to create $\mathrm{HA}$ and $\mathrm{TiO}_{2}$ - $\mathrm{HA}$ layers on the enamel substrate that was thicker than the previously reported layers created by the initial development PJD device. The PJD process was improved in two ways. First, smaller particles were used than in the previous studies. Second, experimental conditions, such as the accelerating pressure and the feed pressure, could be adjusted for the new PJD 
device for using in dental handpieces. As a result, it was considered that the kinetic energy of particles was effectively imparted to give good adhesion properties of the particles. In case of using new PJD device, the thickness of $\mathrm{TiO}_{2}-\mathrm{HA}$ layers was almost equal to that of HA layers. Therefore, it was expected that the $\mathrm{TiO}_{2}$-HA layers would show almost the same good microstructural properties and high stability as those of the previous HA layers.

The hardness of the $\mathrm{TiO}_{2}-\mathrm{HA}$ layers was in the range of approximately 350 $390 \mathrm{Hv}$. These results are almost the same as those obtained for the HA layers created on enamel under the same PJD experimental conditions in the second previous study [2]. On the other hand, the bonding strength of the $\mathrm{TiO}_{2}$ - $\mathrm{HA}$ layers was approximately $15 \mathrm{MPa}$. The micro-tensile bonding strength test used in present study has advantages including more economical use of teeth, better control of regional differences, and better stress distribution at the true interface [23]. The bonding strength of the HA layers created in the second previous study [2] was almost the same as that of the $\mathrm{TiO}_{2}$-HA layers in the present study. Furthermore, several studies [24-26] have reported bonding strengths of composite resin to enamel substrate of 5.9-22.2 MPa; these values are similar to the $15 \mathrm{MPa}$ bonding strength measured for the present $\mathrm{TiO}_{2}$-HA layers. Therefore, it was confirmed that the present PJD process could create the $\mathrm{HA}$ and $\mathrm{TiO}_{2}-\mathrm{HA}$ layers with good material properties on enamel substrates. In addition, our results suggested that addition of $\mathrm{TiO}_{2}$ particles would not influence the creation of layers by the PJD process and the material properties of $\mathrm{HA}$ layers, since the $\mathrm{TiO}_{2}-\mathrm{HA}$ layers showed almost the same excellent material properties as the HA layers.

Thermal-cycling procedures simulate the frequent changes in intraoral temperature induced by eating, drinking, and breathing [27-29]. Thermal stresses are related to mechanical stresses, as differential thermal changes can induce crack propagation through bonded interfaces, and the changing gap dimensions are associated with gap volume changes which pump pathogenic oral fluids in and out of the gaps [30]. According to a review of literature, the sequence of temperatures $35^{\circ} \mathrm{C}, 15^{\circ} \mathrm{C}$, $35^{\circ} \mathrm{C}$, and then $45^{\circ} \mathrm{C}$, with a corresponding dwell sequence of $28 \mathrm{~s}, 2 \mathrm{~s}, 28 \mathrm{~s}$, and $2 \mathrm{~s}$, is suggested to be sufficiently clinically relevant [30]. However, the present study adopted thermal cycling between 5 and $55^{\circ} \mathrm{C}$ for 500 cycles based on the International Organization for Standardization (ISO) specifications to examine the durability of dental materials [16] in order to evaluate under the same conditions as for HA layers in the second previous study [2]. The $\mathrm{HA}$ and $\mathrm{TiO}_{2}-\mathrm{HA}$ layers maintained their three-dimensional morphology even after thermal cycling, as determined from three-dimensional views and SEM images. Table 21.2 showed that there were no significant differences in micro-Vickers hardness and bonding strength before and after the thermal-cycling procedure.

The color difference results of the $\mathrm{TiO}_{2}$-HA layers are shown in Tables 21.3 and 21.4. Between conditions (1) and (2), the $L^{*}$ color parameter significantly increased, the $b^{*}$ color parameter significantly decreased, and the $a^{*}$ parameter was not changed. These results indicate that the created $\mathrm{TiO}_{2}$-HA layers brightened the color of the specimens; their color became slightly bluer. According to the study of evaluation of whitening effects in vitro, whitening occurs mainly by increasing the $L^{*}$ param- 
Table 21.2 Mean values (and standard deviation) of the micro-Vickers hardness and the bonding strength $(n=10)$

\begin{tabular}{l|l|l|l|l}
\hline The first, second, and present study shows captions “29.2," “29.3," and “29.4," respectively \\
\hline & & $\begin{array}{l}\text { The first } \\
\text { study }\end{array}$ & $\begin{array}{l}\text { The second } \\
\text { study }\end{array}$ & $\begin{array}{l}\text { The present } \\
\text { study }\end{array}$ \\
\hline \multirow{2}{*}{$\begin{array}{l}\text { Micro-Vickers } \\
\text { hardness }\end{array}$} & Before thermal cycling & - & $391.6(9.80)$ & $371.3(20.7)$ \\
\cline { 2 - 5 } & After thermal cycling & - & $401.3(9.74)$ & $365.6(27.5)$ \\
\hline \multirow{2}{*}{ Bonding strength } & Before thermal cycling & - & $15.6(5.6)$ & $15.7(1.5)$ \\
\cline { 2 - 5 } & After thermal cycling & - & $14.8(5.9)$ & $15.5(3.8)$ \\
\hline
\end{tabular}

Table 21.3 Mean values (and standard deviation) of CIE L*, $\mathrm{a}^{*}, \mathrm{~b}^{*}$ color parameters for the $\mathrm{TiO}_{2}$-HA layers $(n=5)$

\begin{tabular}{l|l|l|l}
\hline & $\mathrm{L}^{*}$ & $\mathrm{a}^{*}$ & $\mathrm{~b}^{*}$ \\
\hline (1) Before creation of layers & $71.2(1.2)$ & $-2.3(0.3)$ & $-1.4(0.2)$ \\
\hline (2) After creation of layers & $78.1^{\mathrm{a}}(1.1)$ & $-2.3(0.3)$ & $-3.9^{\mathrm{a}}(0.4)$ \\
\hline
\end{tabular}

aThe mean difference is significant at the 0.05 level

Table 21.4 Mean values (and standard deviation) for color difference $\Delta \mathrm{E}^{*}$ of the $\mathrm{TiO}_{2}-\mathrm{HA}$ layers $(n=5)$

\begin{tabular}{l|l}
\hline$\Delta \mathrm{E}$ & $6.7(1.1)$
\end{tabular}

eter (higher $L^{*}$ ), reducing the yellowness (lower $b^{*}$ ), and, to a lesser extent, reducing the redness (lower $a^{*}$ ) [5, 31]. In addition, subjective responses to whiteness improvement are significantly correlated with changes in the $b^{*}$ parameter, and the yellow-blue shift is of primary perceptual importance in tooth-whitening procedures [4]. The reason for the observed color change might be related to selective absorption and reflection of incident light by the $\mathrm{TiO}_{2}$ particles [21]. From the data of $L^{*}, a^{*}$, and $b^{*}$ color parameters, the calculated total color difference $\Delta E$, which evaluates the degree of whitening, was approximately 6.7 units. Several reports have been published about the threshold levels of total color difference that can be visually perceived $[22,32]$. According to a study on intraoral determination of acceptability and perceptibility tolerances for shade mismatch, the color difference in the test denture which $50 \%$ of dentists could perceive was 2.6 units, while the value at which $50 \%$ of dentists would remake due to color mismatch was 5.5 units [32]. This indicates that although the present $\mathrm{TiO}_{2}-\mathrm{HA}$ layers significantly whitened the enamel substrates beyond the perceptible threshold level, their color was mismatched with the optical properties of natural teeth.

In conclusion, the new handpiece-type PJD device could create a thick HA and $\mathrm{TiO}_{2}-\mathrm{HA}$ layer on human enamel substrate, and these layers created demonstrated and maintained excellent microstructural and mechanical properties comparable to those of HA layers in our first previous study even after thermal cycling, which simulated the oral environment. Furthermore, it was confirmed that $\mathrm{TiO}_{2}-\mathrm{HA}$ layers could whiten the tooth surface and showed high color stability. However, we found 
that the whiteness of the layers mismatched the natural tooth color to too great an extent, suggesting that adjustment of the $\mathrm{HA}-\mathrm{TiO}_{2}$ particles' $\mathrm{TiO}_{2}$ content may be necessary to match the natural tooth color. Stated further, if the creation of layers can be adjusted to match the color which patients desires, this raises the possibility that creation $\mathrm{TiO}_{2}$-HA layers by the PJD process may be used clinically as a new treatment for tooth discoloration. Our future research will assess whether layers demonstrating excellent material properties can be created using particles prepared by adjusting the $\mathrm{TiO}_{2}$ concentration.

\subsection{Conclusion}

It was concluded that the new handpiece-type PJD process could create thick HA and $\mathrm{TiO}_{2}$-HA layers on enamel substrates, and these layers demonstrated excellent microstructural and mechanical properties comparable to those of HA layers created by the initial developmental PJD device, even after thermal-cycling procedure. Furthermore, $\mathrm{TiO}_{2}-\mathrm{HA}$ layers could whiten the tooth color and showed high color stability. Creation of $\mathrm{TiO}_{2}$-HA layers by the PJD process might be a valuable new treatment for discolored teeth.

\section{References}

1. Akatsuka R, Sasaki K, Zahmaty MS, Noji M, Anada T, Suzuki O, et al. Characteristics of hydroxyapatite layers formed on human enamel with the powder jet deposition technique. J Biomed Mater Res B Appl Biomater. 2011;98(2):210-6.

2. Akatsuka R, Ishihata H, Noji M, Matsumura K, Kuriyagawa T, Sasaki K. Effect of hydroxyapatite layers formed by powder jet deposition on dentin permeability. Eur J Oral Sci. 2012;120:558-62.

3. Akatsuka R, Matsumura K, Noji M, Kuriyagawa T, Sasaki K. Evaluation of thermal stress in hydroxyapatite layers fabricated by powder jet deposition. Eur J Oral Sci. 2013;121:504-7.

4. Joiner A. Tooth colour: a review of the literature. J Dent. 2004;32:3-12.

5. Lima FG, Rotta TA, Penso S, Meireles SS, Demarco FF. In vitro evaluation of the whitening effect of mouth rinses containing hydrogen peroxide. Braz Oral Res. 2012;26(3):269-74.

6. Dahl JE, Pallesen U. Tooth bleaching-a critical review of the biological aspects. Crit Rev Oral Biol Med. 2003;14:292-304.

7. Hattab FN, Qudeimat MA, Al-Rimawi HS. Dental discoloration: an overview. J Esthet Dent. 1999;11:291-310.

8. Watts A, Addy M. Tooth discoloration and staining: a review of the literature. Br Dent J. 2001;190:309-16.

9. Plotino G, Buono L, Grande NM, Pameijer CH, Somma F. Nonvital tooth bleaching: a review of the literature and clinical procedures. J Endod. 2008;34(4):394-407. 
10. Hannig C, Zech R, Henze E, Dorr-Tolui R, Attin T. Determination of peroxides in salivakinetics of peroxide release into saliva during home-bleaching with Whitestrips and Vivastyle. Arch Oral Biol. 2003;48:559-66.

11. Azer SS, Hague AL, Johnston WM. Effect of bleaching on tooth discoloration from food colourant in vitro. J Dent. 2011;39 Suppl 3:e52-6.

12. Periasamy VS, Athinarayanan J, Al-Hadi AM, Juhaimi FA, Alshatwi AA. Effects of titanium dioxide nanoparticles isolated from confectionery products on the metabolic stress pathway in human lung fibroblast cells. Arch Environ Contam Toxicol. 2015;68(3):521-33.

13. Yu B, Ahn JS, Lim JI, Lee YK. Influence of $\mathrm{TiO}_{2}$ nanoparticles on the optical properties of resin composites. Dent Mater. 2009;25(9):1142-7.

14. Weir MD, Moreau JL, Levine ED, Strassler HE, Chow LC, Xu HH. Nanocomposite containing $\mathrm{CaF}(2)$ nanoparticles: thermal cycling, wear and long-term water-aging. Dent Mater. 2012;28(6):642-52.

15. International organization for standardization. (1994) Guidance on testing of adhesion to tooth structure. ISO TR 11450. Geneva, Switzerland: ISO, 1-14.

16. CIE (Commission International de l'Eclairage). Colorimetry, technical report. CIE Pub. No.15, 2nd ed. Vienna: Bureau Central de la CIE; 1986 (corrected reprint 1996).

17. Akatsuka R, Izumita K, Nishikawa A, Kayaba C, Kadota S, Hoshi T, et al. Exploratory trial to evaluate the hydroxyapatite layer formed by a new dental treatment system. Open J Stomatol. 2015;5:281-6.

18. Park MY, Lee YK, Lim BS. Influence of fluorescent whitening agent on the fluorescent emission of resin composites. Dent Mater. 2007;23(6):731-5.

19. Garcia-Sanz FJ, Mayor MB, Arias JL, Pou J, Leon B, Perez-Amor M. Hydroxyapatite coatings: a comparative study between plasma-spray and pulsed laser deposition techniques. J Mater Sci Mater Med. 1997;8(12):861-5.

20. Quirynen M, Bollen CM. The influence of surface roughness and surface-free energy on supraand subgingival plaque formation in man. A review of the literature. J Clin Periodontol. 1995;22(1):1-14.

21. Power JM. Restorative dental materials. 12th ed. St. Louis: Mosby; 2006. p. 35-42.

22. Ruyter IE, Nilner K, Moller B. Color stability of dental composite resin materials for crown and bridge veneers. Dent Mater. 1987;3(5):246-51.

23. Van Meerbeek B, Peumans M, Poitevin A, Mine A, Van Ende A, Neves A, et al. Relationship between bond-strength tests and clinical outcomes. Dent Mater. 2010;26(2):e100-21.

24. Eminkahyagil N, Gokalp S, Korkmaz Y, Baseren M, Karabulut E. Sealant and composite bond strength to enamel with antibacterial/self-etching adhesives. Int $\mathrm{J}$ Paediatr Dent. 2005; 15:274-81.

25. Kameyama A, Kato J, Aizawa K, Suemori T, Nkazawa Y, Ogata T, et al. Tensile bond strength of one-step self-etch adhesives to Er:YAG laser-irradiated and non-irradiated enamel. Dent Mater J. 2008;27:386-91.

26. Turkun M, Kaya AD. Effect of $10 \%$ sodium ascorbate on the shear bond strength of composite resin to bleached bovine enamel. J Oral Rehabil. 2004;31(12):1184-91.

27. Asaka Y, Amano S, Rikuta A, Kurokawa H, Miyazaki M, Platt JA, et al. Influence of thermal cycling on dentin bond strengths of single-step self-etch adhesive systems. Oper Dent. 2007;32(1):73-8.

28. Saboa VP, Silva FC, Nato F, Mazzoni A, Cadenaro M, Mazzotti G, et al. Analysis of differential artificial ageing of the adhesive interface produced by a two-step etch-and-rinse adhesive. Eur J Oral Sci. 2009;117(5):618-24. 
29. Krejci I, Planinic M, Stavridakis M, Bouillaguet S. Resin composite shrinkage and marginal adaptation with different pulse-delay light curing protocols. Eur $\mathrm{J}$ Oral Sci. 2005;113(6):531-6.

30. Gale MS, Darvell BW. Thermal cycling procedures for laboratory testing of dental restorations. J Dent. 1999;27(2):89-99.

31. International Commission of Illumination. Recommendations on uniform colour spaces, color difference equations and psychometric colour terms. CIE Publication 1978;15 Suppl 2.

32. Douglas RD, Steinhauer TJ, Wee AG. Intraoral determination of the tolerance of dentists for perceptibility and acceptability of shade mismatch. J Prosthet Dent. 2007; 97(4):200-8.

Open Access This chapter is distributed under the terms of the Creative Commons Attribution 4.0 International License (http://creativecommons.org/licenses/by/4.0/), which permits use, duplication, adaptation, distribution and reproduction in any medium or format, as long as you give appropriate credit to the original author(s) and the source, provide a link to the Creative Commons license and indicate if changes were made.

The images or other third party material in this chapter are included in the work's Creative Commons license, unless indicated otherwise in the credit line; if such material is not included in the work's Creative Commons license and the respective action is not permitted by statutory regulation, users will need to obtain permission from the license holder to duplicate, adapt or reproduce the material. 